\title{
Conceivable Differences between the Sexes for the Associations of Patient Characteristics with Locations Affected by Hidradenitis Suppurativa
}

\author{
Kelsey R. van Straalen \\ Department of Dermatology, Erasmus University Medical Center, Rotterdam, The Netherlands
}

\section{Keywords}

Acne inversa - Locations · Phenotype

\section{Dear Editor,}

Recently, a cross-sectional study assessing the associations between patient characteristics and affected locations in patients with hidradenitis suppurativa (HS) was published in Dermatology by Benhadou et al. [1].

We acknowledge the importance of this work. However, we argue that the results might not be as readily interpretable as suggested by the authors. The authors recognize the influence of sex on the distribution of HS lesions and touch upon the difference in clinical phenotypes between the sexes [2]. Nonetheless, there are more reasons to assume that HS manifests differently in men and women. First, the prevalence of HS differs greatly between the sexes; 137 per 100,000 (95\% CI, 136-139 per $100,000)$ in women compared with 58 per $100,000(95 \%$ CI, 57-59 per 100,000) in men [3]. Second, a subgroup of women are known to experience peri-menstrual HS flares and oral contraceptives can relieve HS symptoms in these patients $[4,5]$. Based on this knowledge, it is conceivable that part of the pathophysiology could differ between the sexes and related predisposing factors might have a dif-

\begin{tabular}{ll}
\hline karger@karger.com & (c) 2020 The Author(s) \\
Published by S. Karger AG, Basel & \\
Targer.com/drm & $\begin{array}{l}\text { This article is licensed under the Creative Commons Attribution- } \\
\text { NonCommercial-NoDerivatives 4.0 International License (CC BY- } \\
\text { NC-ND) (http://www.karger.com/Services/OpenAccessLicense). } \\
\text { Usage and distribution for commercial purposes as well as any dis- } \\
\text { tribution of modified material requires written permission. }\end{array}$
\end{tabular}

ferent effect in men and women. Therefore, the degree and possibly even the direction of the associations between patient characteristics and the affected locations might be different for men and women. We argue that assessing the association of patient characteristics with affected locations separately for men and women could lead to valuable new insights.

Moreover, the authors state that their results are in favour of regional associations, for example for the buttocks, subgluteal, and anal regions. However, the associations found between these and other neighbouring regions might be more suggestive of a lack of clear definitions of these regions, as briefly mentioned by the authors in the discussion. Moreover, several regions, e.g., the "subgluteal" region, are not commonly counted as separate entities in clinical HS trials or daily practice. In light of the lack of clearly defined anatomical regions for the scoring of HS and the use of non-standard body areas in this study, it would be of added value to know whether all patients were scored by the same or by different physicians. In addition, it would be of interest to combine these difficult to distinguish regions into more accepted anatomical regions and see what independent associations remain [6].

The authors have performed elaborate multivariate analyses. However, it should be noted that Hurley stage is 
a categorical variable which will result in different odds for the different Hurley stages in the logistic regression models. Therefore, we suggest specifying the odds for Hurley stage II and III (with Hurley stage I as the reference category) for each location.

In conclusion, we commend the authors for their extensive research on the association between patient characteristics and affected locations in a large sample of HS patients. Nonetheless, the results need to be interpreted with care as they are subject to a lack of clearly defined anatomical regions and possible interrater variability. Assessing the association between patient characteristics and affected regions could lead to valuable new insights and shed more light on the differences between the sexes in patients with HS.

\section{Key Message}

Separately assessing associations of patient characteristics with affected locations for the sexes could provide valuable insights.

\section{Disclosure Statement}

The author has no conflict of interest to declare.

\section{Funding Sources}

This letter has no funding source.

\section{Author Contributions}

K.R. van Straalen is responsible for the conceptual design and writing of this letter.

\section{References}

1 Benhadou F, Villani A, Guillem P. Which factors determine affected sites in hidradenitis suppurativa? Dermatology. 2020;236(1):1520.

2 Bianchi L, Caposiena Caro RD, Ganzetti G, Molinelli E, Dini V, Oranges T, et al. Sex-related differences of clinical features in hidradenitis suppurativa: analysis of an Italianbased cohort. Clin Exp Dermatol. 2019 Jul; 44(5):e177-80.
3 Garg A, Kirby JS, Lavian J, Lin G, Strunk A. Sex- and age-adjusted population analysis of prevalence estimates for hidradenitis suppurativa in the United States. JAMA Dermatol. 2017 Aug;153(8):760-4.

4 Vossen AR, van Straalen KR, Prens EP, van der Zee HH. Menses and pregnancy affect symptoms in hidradenitis suppurativa: A cross-sectional study. J Am Acad Dermatol. 2017 Jan;76(1):155-6.
5 van Straalen KR, Schneider-Burrus S, Prens EP. Current and future treatment of hidradenitis suppurativa. Br J Dermatol. 2018 Jul. https://doi.org/10.1111/bjd.16768.

6 Zouboulis CC, Nogueira da Costa A. Standardized photographic documentation of hidradenitis suppurativa/acne inversa. Dermatology. 2019;235(1):51-4. 